\title{
There's an App for That? Ethical consumption in the fight against trafficking for labour exploitation
}

\author{
Stephanie A. Limoncelli
}

\section{Abstract}

Among the market-based strategies being used to fight trafficking for labour exploitation are apps aimed at encouraging ethical consumption. Such apps have surfaced in tandem with the increased involvement of businesses in anti-trafficking efforts and the promotion of social entrepreneurism. In this article, I describe and critically analyse three apps aimed at individual consumers, arguing that they do little to actually address labour exploitation. They rest on questionable assumptions about consumption, employ problematic assessment methodologies, and rely on business models that do more to provide opportunities for social entrepreneurs in the burgeoning anti-trafficking field than solutions for labour exploitation in the global economy.

Keywords: anti-trafficking strategies, consumer activism, ethical consumption, forced labour, labour exploitation, mobile apps

Please cite this article as: S A Limoncelli, 'There's an App for That? Ethical consumption in the fight against trafficking for labour exploitation', AntiTrafficking Review, issue 14, 2020, pp. 33-46, https://doi.org/10.14197/ atr.201220143

\section{Introduction}

As technology has become increasingly prominent in anti-human trafficking efforts, ${ }^{1}$ mobile applications, or apps, designed to run on phones and tablets have

$1 \quad$ M Thakor and d boyd, 'Networked Trafficking: Reflections on technology and the anti-trafficking movement', Dialectical Anthropology, vol. 37, no. 2, 2013, pp. 277-290, https://doi.org/10.1007/s10624-012-9286-6. See also, J L Musto and d boyd, 'The Trafficking-Technology Nexus', Social Politics: International studies in gender, state \& society, vol. 21, no. 3, 2014, pp. 461-483, https://doi.org/10.1093/sp/jxu018. 
surfaced as one tool by which to address exploitation in the global economy. ${ }^{2}$ Many such apps are aimed at increasing surveillance and reporting of trafficking cases or facilitating public awareness about it, but as concern with labour exploitation in global supply chains has become a bigger focus of anti-trafficking efforts, a new crop of apps has emerged: ethical consumption apps. These are apps that provide consumers with information and/or ratings of major brands with the hope that buyers will make conscientious purchases to reward 'good' companies and/or avoid those that are benefiting from labour exploitation. Ethical consumption apps are one tangible aspect of market-led approaches to antitrafficking work and the social entrepreneurism that is increasingly prominent in the field. ${ }^{3}$

In this article, I ask whether ethical consumption apps are well positioned to fight trafficking for labour exploitation and forced labour in supply chains; this is part of a broader project interrogating the role of businesses and market-based strategies in anti-trafficking work. After providing some background information on ethical consumption strategies and their use in anti-trafficking efforts, I describe the apps; critically analyse some of their underlying assumptions; outline problems in their assessment methodologies; and raise questions about the business of activism. I argue that the apps do little to address the limitations of consumption-based strategies for fighting labour exploitation.

\section{Background}

The language and goals of ethical consumption have become increasingly popular in wealthy capitalist societies and have engendered debate among academics in a variety of disciplines. ${ }^{4}$ Proponents see ethical consumption as an intriguing form of activism, one that turns markets into venues for political action, broadens political participation among those who might not otherwise become involved in electoral politics, and forces companies to address a variety of social and

2 For a recent list of technological initiatives that includes examples of different apps, see: BSR, 'List of Technology Tools and Initiatives Identified by Tech against Trafficking - January 15, 2019', retrieved 7 January 2020, https:/www.bsr.org/files/ BSR_list_of_technology_tools_identified_by_tech_against_trafficking.

3 On the increasing role of businesses in anti-trafficking work, see, e.g., E Bernstein, 'Redemptive Capitalism and Sexual Investability', in A Shola Orloff et al. (eds.), Perverse Politics? Feminism, anti-imperialism, multiplicity, Emerald Group Publishing Limited, Bingley, 2016, pp. 45-80. See also, S Henriksen, 'Consuming Life after Anti-Trafficking', Anti-Trafficking Review, issue 10, 2018, pp. 14-33, https://doi. org/10.14197/atr.201218102.

4 T Lewis and E Potter, Ethical Consumption: A critical introduction, Routledge, New York, 2011. 
environmental problems. ${ }^{5}$ Critics not only question the efficacy of ethical consumption, but also raise concerns about the ways in which it reinforces neoliberalism. They argue that ethical consumption individualises responsibility for addressing social problems, reinforces corporate self-regulation and a diminished role for states, diverts attention away from structural processes contributing to labour exploitation, and provides cover for corporations to market themselves as 'ethical' while actually doing little to change existing business practices that contribute to the problems they purport to help solve. ${ }^{6}$ Other scholars fall somewhere in between, noting that companies sometimes respond to consumer pressure under certain conditions and that cultural shifts towards expectations of corporate accountability are in themselves a form of progress. ${ }^{7}$

Despite concerns about ethical consumption raised by academics, stakeholders in all three domains of anti-trafficking work-government, civil society, and business - have found agreement in focussing on consumption-based strategies. Accordingly, governments in Western Europe and the United States have been implementing transparency legislation intended to allow consumers to gain information about companies' anti-trafficking efforts, ${ }^{8}$ and businesses and entrepreneurs have been partnering with NGOs or striking out on their own to promote consumption-based initiatives. Underlying these efforts are two main assumptions: that consumers lack information by which to make decisions and take action, and that markets are a powerful force for fighting labour exploitation.

Digital technology is being employed in many consumption-based initiatives, offering the means to centralise and share information as well as potentially build

5 M Micheletti, Political Virtue and Shopping: Individuals, consumerism, and collective action, Palgrave Macmillan, New York, 2003. See also, M Micheletti and D Stolle, 'Mobilizing Consumers to Take Responsibility for Global Social Justice', The ANNALS of the American Academy of Political and Social Science, vol. 611, no. 157, 2007, pp. 157-175, https://doi.org/10.1177/0002716206298712.

6 J Littler, 'What's Wrong with Ethical Consumption?', in T Lewis and E Potter (eds.), Ethical Consumption: A critical introduction, Routledge, New York, 2011.

7 T Bartley et al., Looking Behind the Label: Global industries and the conscientious consumer, Indiana University Press, Bloomington, 2015.

8 For a critical analysis of these efforts, see: N Phillips, 'Private Governance and the Problem of Trafficking and Slavery in Global Supply Chains', in Louise Waite et al. (eds.), Vulnerability, Exploitation and Migrants, Palgrave Macmillan, Basingstoke, 2015, pp. 15-27. See also, S A Limoncelli, 'Legal Limits: Ending human trafficking in supply chains', World Policy Journal, vol. 34, no. 1, 2017, pp. 119-123, https://doi. org/10.1215/07402775-3903628. 
communities of interest or activism. ${ }^{9}$ This is very much in keeping with trends in other advocacy fields. As sociologists Dale and Kyle note 'market-led business models...celebrate the challenge of solving a variety of social problems, including many relating to inequality and injustice, by means of digital technology - with a heavy emphasis on smart technology, cloud-based computing, and IT infrastructure development'. ${ }^{10}$ Social problems, in this view, are problems of the market and can best be solved with digital technology.

Scholars who study anti-trafficking efforts are just beginning to catch up to the role that technology can play in consumption-based strategies, in part because many initiatives are relatively recent, ${ }^{11}$ and perhaps in part because of the transient nature of some of the earliest experiments. For example, Free2Work, an app ranking companies based on their labour practices, premiered in 2011, but is no longer available. ${ }^{12}$ Likewise, the Made in a Free World App debuted in 2011, allowing users to scan products to get a score indicating the likely number of forced laborers that have been involved in creating the product at some stage of the process of production', but those who search for it online today will not find it. Instead, a donation button on an old version of the organisation's website links to a software platform aimed at mapping out supply-chain risks for buyers in Fortune 500 companies. $^{13}$

Some scholars, however, are already casting a sceptical eye at digital initiatives aimed at educating consumers. For example, they have raised concerns about the interactive online 'slavery footprint' survey created by Made in a Free World that asks about people's consumer spending habits and then reveals how many 'slaves'

9 K Humphery and T Jordan, 'Mobile Moralities: Ethical consumption in the digital realm', Journal of Consumer Culture, vol. 18, no. 4, 2018, pp. 520-538, https://doi. org/10.1177/1469540516684188.

10 J Dale and D Kyle, 'Smart Humanitarianism: Re-Imagining human rights in the age of enterprise', Critical Sociology, vol. 42, no. 6, 2016, pp. 783-797, https://doi. org/10.1177/0896920516640041.

11 Humphery and Jordan.

12 Free2Work et al., 'Free2work Launches Barcode Scanning App 2.0, Increasing Consumer Power', International Labor Rights Forum, retrieved 20 January 2020, https://laborrights.org/releases/free2work-launches-barcode-scanning-app-20-increasing-consumer-power.

13 Slavery Footprint, 'Made in a Free World App', retrieved 15 January 2020, http:// slaveryfootprint.org/about/\#getapp. 
work for them. ${ }^{14}$ They have pointed out its binary narrative of heroes and villains, its uncritical distinction between free and forced labour, and the implication that wealthy western consumers are heroes 'saving' distant racialised others from villainous producers or suppliers in countries with developing economies. ${ }^{15}$ They have also noted that corporations, in contrast, are given the benefit of the doubt, cast as innocent victims that do not know what happens further up supply chains and/or potential heroes deserving of sales when they press suppliers for transparency. ${ }^{16}$ Thus far, these scholars suggest, the use of digital technology simply reproduces many of the problems of anti-trafficking campaigns more generally. ${ }^{17}$

I share the concerns raised by these scholars and seek to add to the critiques via an analysis of ethical consumption apps being used to fight trafficking for labour exploitation. Given that two of the main assumptions of ethical consumption apps are that consumers lack information by which to make decisions and that markets are a powerful means for fighting labour exploitation, I consider the ways in which the apps are framing consumption and providing information to users. I examine both the structure and assessment methodologies of the apps, as well as the organisational actors who promote them. Doing so allows consideration of the implications for anti-trafficking advocacy, including whether the apps are well placed to achieve their intended purpose and whether or not they reproduce the problems highlighted by critics of ethical consumption.

\section{The Apps}

The three examples considered here, Buycott, Good On You, and Shop Ethical!, are all ethical consumption apps that provide rankings or recommendations to assist users in making purchasing decisions based, at least in part, on issues of labour exploitation. The apps were identified via Google Play and the Apple App Store, and while these platforms do include other ethical consumption apps, they were excluded from this analysis because they did not address labour exploitation explicitly (i.e., they were focussed only on other problems).

14 See: A Page, 'How Many Slaves Work for You? Race, new media, and neoliberal consumer activism', Journal of Consumer Culture, vol. 17, no. 1, 2017, pp. 46-61, https://doi.org/10.1177/1469540514553716, and E O’Brien, 'Human Trafficking and Heroic Consumerism', International Journal for Crime, Justice and Social Democracy, vol. 7, no. 2, 2018, pp. 51-66, https://doi.org/10.5204/ijcjsd.v7i4.430.

15 Ibid.

16 O’Brien.

17 E O'Brien and H Berents, 'Virtual Saviours: Digital games and anti-trafficking awareness-raising', Anti-Trafficking Review, issue 13, 2019, pp. 82-99, https:// doi.org/10.14197/atr.201219136. 
As with other recent analyses of digital technology in anti-trafficking advocacy, I qualitatively examined the structure and content of the apps, as well as supportive information about the apps from the developers. ${ }^{18}$ The emphasis is on their structure and content rather than their actual use; this is not meant to downplay the agency of users, but rather to highlight the importance of the social construction of the apps. ${ }^{19}$ In keeping with the call for broader sociological and political critiques of the turn to business and market approaches in advocacy efforts more generally, I proceeded inductively to identify common characteristics of the apps and their implications. ${ }^{20}$

Buycott, a free app with over a million downloads, was developed by the founder of a small privately-held company based in the United States. ${ }^{21}$ The app allows users to scan the barcodes of a wide array of products and provides information on whether brands are in conflict with user-generated campaigns that may be joined on the site. The campaigns cover a variety of issues but have included some that specifically target human trafficking $(103,615$ members); child labour in the cocoa industry (172,292 members); child labour more generally $(73,648$ members); slavery in fishing supply chains (52,128 members); and sweatshop labour (28,611 members). ${ }^{22}$ In addition to joining campaigns and looking up or scanning particular products, users can set up a profile and post comments about particular companies, categorise companies to support or avoid, provide links to relevant online information about companies, or use the app to notify companies about the user's intention to support or boycott them. The app also encourages users to connect via Facebook and/or invite people from their contact lists to join and to follow and be followed by other users.

Good On You, a privately held company that markets itself as a 'commercial social impact business' jointly owned by the non-profit Ethical Consumers Australia and its founding staff, has a free app focussed on brands selling clothing, footwear and accessories. ${ }^{23}$ Users can search for products by category or browse brands to find company profiles with links to relevant online information and brand rankings: 1 (we avoid); 2 (not good enough); 3 (it's a start); 4 (good) and 5 (great).

18 Ibid.

19 Humphery and Jordan, pp. 528-529. See also, N Grant, 'The Antiracism App: Methodological reflections for theory and practice', Critical Literacy: Theories and practices, vol. 8, no. 1, 2014, pp. 20-35.

20 Dale and Kyle, p. 786

21 Buycott Inc., 'Buycott - Barcode Scanner (Version 3.1.2) [Mobile Application Software] Retrieved from Google Play Store', accessed 17 January 2020.

22 Ibid.

23 Good On You, 'Good On You (Version 4.0.11) [Mobile Application Software] Retrieved from Google Play Store’, accessed 17 January 2020. 
The rating on labour considers child labour, forced labour, freedom of association, and the payment of a living wage. ${ }^{24}$ The rating also includes consideration of a brand's supplier relationship and auditing practices, though specific details about how these factors are evaluated and weighted are lacking. The app, which has $100,000+$ downloads, provides links to the company's website so that users can purchase items directly; it also uses an algorithm to suggest similar brands for users to consider; showcases ethical fashion news articles; and provides offers from highly rated brands that users can use to obtain a discount should they choose to purchase items from them. ${ }^{25}$

Shop Ethical! is a paid app and pocket guide that provides information on the social and environmental records of companies. It is a project of the Ethical Consumer Group, a community-based non-profit organisation and network based in Australia and has 5,000+ downloads. ${ }^{26}$ Like Buycott, the app provides a barcode scanner to search for products across a broad range of industries (approximately 67,000 products at the time of this analysis), but rather than relying on userprovided assessments, the app provides brand grades from A to $\mathrm{F}$ based on staff assessments. ${ }^{27}$ Users who purchase the app can browse by product category to find particular companies and view a company profile with ownership and contact information and links to articles and reports detailing positive and negative aspects of environment, animal welfare, social, and business practices. Various forms of labour exploitation can be cited in their ratings, such as the use of sweatshops, lack of worker rights, low wages, wage theft, practices or conditions involving workplace hazards, and child labour. Some product categories provide links to the websites of alternative brands, not typically rated in the app, but presumably evaluated by staff as preferable.

\section{Assumptions about Consumption and Their Implications}

The apps are unified in their portrayal of consumers as a powerful force for change and markets as the venue by which to accomplish it. Buycott 'helps you use your dollars to create change' ${ }^{28}$ and encourages individuals to 'vote with your wallet'. ${ }^{29}$ Shop Ethical! states that 'the power consumers have to change the conduct and

\footnotetext{
24 Ibid. See the 'About Us' and 'How We Rate Brands' sections of the app.

25 Ibid.

26 Outware Mobile, 'Shop Ethical! (Version 1.9.5) [Mobile Application Software] Retrieved from Google Play Store', accessed 17 January 2020.

27 Ibid. See the 'Introduction' and 'About Our Assessments' sections of the app.

28 Buycott Inc.

29 'Buycott | Vote with Your Wallet - Upc Lookup Database, Find Barcode Scanner, Boycott', https://www.buycott.com, accessed 24 January 2020.
} 
actions of companies comes from their dollars and the choices they make as consumers'. ${ }^{30}$ Good On You advises the consumer to 'wear the change you want to see', because 'there's an app for that'. The overt message is that 'by choosing ethically, you become the solution'. ${ }^{31}$ However, there is no discussion of the mechanisms by which users' purchasing decisions translate into company action. The act of purchasing itself is what is stressed, decontextualised from broader issues of when, how, and under what conditions ethical purchases are effective or when they might have unintended consequences for workers.

The overall emphasis in all three apps is on encouraging more consumption rather than simply boycotting brands; this is something that appeals to businesses and workers alike since boycotts can harm both groups when there is a drop in demand. The apps provide no acknowledgement, however, of a central contradiction of this approach: that consumption itself can be a driving factor contributing to labour exploitation. ${ }^{32}$ The very phones and tablets being used to access the apps provide a good example: they are known to have highly exploitive labour practices in their supply chains, something that is exacerbated by high demand and short timeframes for production. ${ }^{33}$

Furthermore, in privileging the consumer as the locus of action and power, the apps implicitly and explicitly reinforce neoliberal tenets advocating reduced government involvement in social and economic life. Shop Ethical!, for example, directly promotes the narrative that governments are not the answer to social problems. The app states, 'We look beyond government control of the way we live and how companies act, believing that real power should lie in the hands of individuals and communities.' 34 The other two apps are not as direct, but nonetheless omit any discussion of the role of governments in addressing the worst forms of labour exploitation in supply chains. For example, in noting several companies that fail to provide information about what, if anything, they do to address labour issues, Good On You simply hopes that naming them and urging them to 'start thinking about doing the right thing' will be enough. ${ }^{35}$

30 Outware Mobile. See the 'Get Informed' and 'Using Consumer Power' sections.

31 Good On You.

32 J O'Connell Davidson, 'Absolving the State: The trafficking-slavery metaphor', Global Dialogue, vol. 12, issue 2, 2012, pp. 31-41, p. 38.

33 See: Humphery and Jordan, p. 533 on this point.

34 Outware Mobile.

35 Good On You. See 'The 2019 Ethical Fashion Naughty and Nice List'. 
The apps also reinforce individualised responsibility for addressing trafficking in ways that can channel dissent away from collective action. ${ }^{36}$ For example, Shop Ethical! makes a point of telling users that 'there is no right way to be an ethical consumer' and 'what you value will determine the criteria you see as most important'. ${ }^{37}$ It is left to individuals to determine not only what constitutes labour exploitation, but also whether it even warrants action. The user-generated campaigns to address labour exploitation on Buycott also reinforce this tendency. Initiated by separate individual users without coordination, users must peruse campaigns addressing different aspects of trafficking and forced labour, deciding whether or not to support or boycott particular companies for different reasons.

This emphasis on individual action is complicated by contradictory or limited information that can make it difficult for users to determine what to do. For example, commenting on the 'Avoid Sweatshop Labour' campaign on Buycott, a user stated, 'I thought it was ok to shop for Nike, new Balance and Hanes because they are part of the Fair Labour Association... That having been said, maybe the standards for FLA aren't as good as what this campaign wants, I don't know. ${ }^{38}$ Furthermore, in individualising both the interpretation of exploitation and action to address trafficking, the apps provide an avenue for counter-narratives to thrive. Buycott provides a particularly ironic example: it has an anti-union campaign calling on people to avoid a number of companies that are unionised or advertise their products as 'union-made'. ${ }^{39}$

In their assumptions about consumption, the apps reinforce the concerns that critics of ethical consumption have raised. Individual consumer choice does not provide concrete mechanisms, government-led or otherwise, to shift the responsibility for trafficking and forced labour back to companies and their suppliers. It does even less to ensure that workers' voices are included or that they are empowered to organise and address working conditions. Nor does it question and challenge the systematic causes of these problems that have persisted despite decades of pressure for corporate social responsibility. ${ }^{40}$

36 P Dauvergne and G Lebaron, Protest Inc.: The corporatization of activism, Polity Press, Cambridge, 2014.

37 Buycott Inc.

38 Ibid.

39 Ibid.

40 Bartley et al. 


\section{The Quandaries of Quantification}

The apps use digital technology to centralise information about companies and help users gather and make available information that they might not otherwise know or seek out on their own. All three of the apps aim to show connections between various products and parent companies, helping to map out the mazelike brand portfolios of large corporations. This type of information is currently very limited, however, and though all of the apps rely on users to identify new products that are not already included, it is a huge challenge to keep track of thousands of products and their associated companies. ${ }^{41}$ For example, on Buycott, one can find advice to avoid Kraft Foods (now Mondelez) for sourcing cocoa from areas with child slavery and to support Cadbury because they are doing a better job. However, the first company is actually the parent of the second company. ${ }^{42}$

More problematic is that the apps attempt to provide a seemingly objective assessment of companies when the reality is much more complicated. All of the apps rely on publicly available information and reports by NGOs, media, certification schemes and initiatives, other ranking apps, and statements by the companies themselves. These are ad hoc, scattershot, and constrained by time lags, making it inevitable that information will be incorrect, incomplete, or outof-date. For example, Shop Ethical! and Buycott include sources that are more than five years old and both have links to reports that are no longer available. Shop Ethical! provides the most sources for the user to access, but they are neither comprehensive nor contextualised; rather, they are listed under columns of 'praise' and 'criticism', with the user left to make sense of the masses of information on their own. ${ }^{43}$

Users must also determine the credibility of sources themselves. For example, the apps sometimes cite sources that have been criticised for being too business-friendly without referencing that fact. ${ }^{44}$ Good On You has in the past relied on the Baptist World Aid Australia's Ethical Fashion Report in their profiles of companies' labour practices, but that report relies on company-provided data that is not augmented by site inspections. The organisation itself therefore cautions that, 'It is important to note that a high grade does not mean that a company has a supply chain that

41 Humphery and Jordan.

42 Buycott Inc. See the list entitled 'Boycott chocolate produced by child slaves campaign'.

43 Outware Mobile.

44 One of these is the Fair Labor Association. See: J Esbenshade, Monitoring Sweatshops: Workers, consumers and the global apparel industry, Temple University Press, Philadelphia, 2004, pp. 165-197. 
is free from exploitation. ${ }^{35}$

The apps not only rely on problematic sources, they also use different methodologies to determine their rankings, resulting in varying assessments. For example, Good On You gives the clothing company Wrangler a middle grade (3 out of 5 points or 'it's a start'), noting its code of conduct and that it traces its supply chain. ${ }^{46}$ Shop Ethical!, meanwhile, gives the same company an F, citing its role in perpetuating low wages and long working hours in Bangladesh, wage theft in Haiti, and accusations of child labour. ${ }^{47}$ Likewise, the two apps differed in their assessment of Gap, a well-known clothing company, with Good On You again providing a medium grade, favourably noting the brand's code of conduct and progress tracing its supply chain. ${ }^{48}$ Citing numerous reports of the company's continued sourcing from countries and suppliers with low wages, long working hours and child labour; complicity in wage theft, and their refusal to sign the Accord on Fire and Building Safety in Bangladesh, Shop Ethical! gave the company an $\mathrm{F}^{49}$ One can find inconsistencies even within a single app: because Buycott allows users to determine their own criteria in making assessments, one may find examples of companies that users are told both to support and to avoid if they are concerned about trafficking for labour exploitation and forced labour in supply chains. For example, Coca-Cola is listed as a beverage company to support because of its compliance with transparency legislation, but also categorised as one to avoid because of the problem of child labour in its sugar supply chains. ${ }^{50}$

Scholars across disciplines have repeatedly called attention to the political and social implications of quantification and classification in anti-trafficking efforts, and ethical consumption apps need to be considered in this light as well. ${ }^{51}$ Their effort to neatly categorise the companies and their labour practices obscures and

45 Baptist World Aid Australia, 'Ethical Fashion Report Faqs', retrieved 17 January 2020, https://baptistworldaid.org.au/ethical-fashion-report-faqs.

46 Good On You.

47 Outware Mobile.

48 Good On You.

49 Outware Mobile.

50 Buycott Inc.

51 See, e.g., P Andreas and K M Greenhill (eds.), Sex, Drugs, and Body Counts: The politics of numbers in global crime and conflict, Cornell University Press, Ithaca, 2010; $S$ Molland, 'In Search of the Perfect Method: Reflections on knowing, seeing, measuring and estimating human trafficking', in S Yea (ed.), Human Trafficking in Asia: Forcing issues, Routledge, London, 2014, pp. 101-117; S E Merry, The Seduction of Quantification: Measuring human rights, gender violence, and sex trafficking, University of Chicago Press, Chicago, 2016; F P Bernat and T Zhilina, 'Trafficking in Humans: The TIP Report', Sociology Compass, vol. 5, no. 6, 2011, pp. 452-462, https://doi.org/10.1111/j.1751-9020.2011.00380.x. 
confuses more than enlightens. ${ }^{52}$ The rankings may be intended to provide a shorthand way for individual consumers to assess a company's labour practices, but in the process, they take the locus of attention away from the workers themselves and instead make the consumer's experience the prime consideration. ${ }^{53}$ Workers are represented only indirectly in this process, and their experiences, thoughts and opinions on how companies might be assessed or what consumers should know or do are not addressed.

\section{Technology and the Business of Activism}

Technology is not simply being used as a tool in anti-trafficking efforts; it is a means of generating income and livelihoods for individual entrepreneurs and businesses finding their way into anti-trafficking work. Good On You, for example, is privately held, financed at first by its two founders as well as crowdfunding campaigns, grants, and social investors, but its ongoing income is now from affiliate marketing links. ${ }^{54}$ The links direct users to companies' websites so that they can purchase items directly, even from companies that they rate as two out of five or 'not good enough'. Good On You then receives a commission for purchases made within a thirty-day period. The app also generates income by connecting its users to well-rated brands via special offers, sponsored blog articles and other advertising. A third source of revenue for the company is access to their brand database and 'expertise on ethical sourcing' which they market to retailers worldwide 'who are looking to monitor the performance of their brand portfolio, stock more ethical brands in their stores, and communicate the ethics of brands to their customers'. ${ }^{55}$

Buycott, too, has a similar trajectory, developed by a freelance programmer who initially self-funded the project, registered as a privately held company, received money from investors, and according to its website, now sells subscriptions to its universal product code (UPC) database. ${ }^{56}$ Only Shop Ethical!, owned by a nonprofit, takes a different approach, charging five dollars for the app. The app developer that partners with Shop Ethical! receives 35 per cent of the amount;

52 Merry.

53 O’Brien. See also: Esbenshade, pp. 201-207.

54 Good On You, 'Good On You Faqs', retrieved 24 January 2020, https://goodonyou. eco/faqs.

55 Ibid.

56 K Eli et al., 'Digital Food Activism: Values, expertise and modes of action', in T Schneider et al. (eds.), Digital Food Activism, Routledge, Abingdon, 2017, pp. 1-24, http://doi.org/10.31235/osf.io/nx27d. See also: Buycott, retrieved 22 February 2020, https://www.buycott.com/api. 
Apple/Google receive 30 per cent and the non-profit receives 35 per cent. ${ }^{57}$ Along with the hard copy of the report, the app is the main source of income for the organisation. ${ }^{58}$

Both for-profit companies collect information about users that can be used for market research and targeted advertising, and sold to interested third parties. They both also, in part, rely on consumers to contribute to the products and goods they are selling, helping to crowdsource information and share and market brands. This is what social scientists have termed 'collaborative coproduction' involving both the 'capture and market exploitation of information about individuals and their marketing "profiles" and 'managerial functions, such as marketing and innovation'. ${ }^{9}$ The users of the apps create value for the owners. It is not surprising, then, to find the apps more centrally concerned with user-consumers rather than the workers the apps are theoretically intended to help. The focus on consumers takes the locus of power away from the workers, effectively sidelining them as objects to be used in the promotion of particular brands rather than as partners in the fight against labour trafficking and forced labour. ${ }^{60}$

\section{Conclusion}

In this article, I highlight a number of problems with ethical consumption apps in the fight against trafficking for labour exploitation. They rest on questionable assumptions about the efficacy of consumption in ameliorating social problems; they are plagued by difficulties of assessment methodologies that conceal more than they reveal; and they create new markets for social entrepreneurs but lack accountability for consumers or for the workers they purport to help. The apps, as well as other consumption-based strategies, may have a place in the fight against labour exploitation. However, as social scientists have noted, in order to be successful, consumer pressure cannot be left to individuals. ${ }^{61}$ In organised campaigns, groups can marshal the time and expertise needed to successfully research, plan, and strategise action rather than passing these tasks onto 'consumer experts'. They can also press for action by mobilising larger buyers, such as

57 Ethical Consumer Group, 'Faq', retrieved 24 January 2020, https://www.ethical.org. au/about/faq.

58 Ibid.

59 M-A Dujarier, 'The Three Sociological Types of Consumer Work', Journal of Consumer Culture, vol. 16, no. 2, 2014, pp. 555-571, https://doi.org/10.1177/ 1469540514528198.

60 Esbenshade.

${ }^{61}$ G Seidman, Beyond the Boycott, Russell Sage Foundation, New York, 2007. See also, T Bartley et al. 
governmental and non-profit organisations, that could take part in campaigns by checking their own supply chains and working towards avoiding purchases from companies with ongoing exploitation.

Against continued calls for ethical consumption to combat trafficking for labour exploitation, ${ }^{62}$ I have argued that this approach is limited and that the apps do little to change exploitative labour practices. The apps are constrained by their divorce from broader structural mechanisms that are helping to create labour exploitation. They do little to promote collective action and even less to ensure development and implementation of labour laws, the regulation of suppliers, due diligence by companies, or real penalties for businesses that eschew their responsibilities to observe labour legislation. Technological initiatives are tools, not solutions, and they cannot be a substitute for the hard work of partnering with and supporting worker organising, regulating corporate malfeasance, and addressing supply-side factors driving the most extreme forms of labour exploitation in the global economy.

Stephanie A. Limoncelli is Associate Professor of Sociology at Loyola Marymount University in Los Angeles, California, USA. She has authored a variety of articles on anti-trafficking activism as well as a book, The Politics of Trafficking: The first international movement to combat the sexual exploitation of women (Stanford University Press, 2010). Her current research examines the influence of business in anti-trafficking efforts addressing labour exploitation and the collaborations occurring between businesses and non-governmental organisations. Email: stephanie.limoncelli@lmu.edu

62 A A Aronowitz, 'Regulating Business Involvement in Labor Exploitation and Human Trafficking', Labor and Society, vol. 22, no. 1, 2019, pp. 145-164, https://doi. org/10.1111/lands.12372. 